\title{
GAMBARAN TINGKAT KECEMASAN PASIEN DI INSTALASI GAWAT DARURAT
}

\author{
Serenity Prayer Amiman \\ Mario Katuuk \\ Reginus Malara \\ Program Studi Ilmu Keperawatan Fakultas Kedokteran \\ Universitas Sam Ratulangi \\ Email : reyserenityprayer@gmail.com
}

\begin{abstract}
An expression that appear when an individual felt they were in a situation that might be dangerous is called anxious. Fear and anxious is an emotion that appears in health facility. Anxiety appears with a dim without a clear cause that made an indiviual felt uncomfotable with the environment around. Anxiety can also became a signal to prepare an individual to cope with a problem that might came. People with anxiety seems to be tense, worried and affraid, also there are change in physiological. Emergency treatment can make patient to feel fear dan anxious to receive a treatment. An intervention to save lives can be the cause of anxiety since the treatment might cause change on a persons integrity. Anxious is a form of unspesific objek that cause uncomfortable and or might cause death. The purpose of this study is to see the levels of anxiety that might appears on patients at Emergency Department in Bhayangkara Hospital Manado. Design of descriptive to collect data from the respondent using HARS anxiety questionair to measure the levels of anxiety. Samples are 69 respondents that are the patients in Emergency Department in Bhayangkara Hospital. The result indicate that from 69 responden there are 47 responden $(68,1 \%)$ are having severe anxiety.
\end{abstract}

Keyword : Anxiety, Emergency Department

\begin{abstract}
Abstrak: Cemas merupakan suatu perasaan yang muncul saat seseorang berada dalam keadaan yang dapat mengancam keadaan jiwa. Takut dan cemas sebagai emosi yang dirasakan oleh pasien di sarana kesehatan. Kecemasan muncul secara samar tanpa penyebab yang jelas dan dapat membuat seseorang merasa tidak nyaman terhadap keadaan lingkungan sekitarnya. Kecemasan juga dapat menjadi sinyal kepada seseorang untuk mempersiapkan dirinya dalam menghadapi suatu keadaan. Kecemasan ditandai dengan adannya perasaan tegang, khawatir dan ketakutan, serta dapat terjadi perubahan fisiologis. Perawatan gawat darurat membuat pasien takut dan cemas dalam menghadapi tindakan perawatan. Memberikan tindakan penyelamatan jiwa dapat menyebabkan kecemasan karena dapat mengancam integritas jiwa. Cemas merupakan bentuk reaksi yang tidak spesifik yang menimbulkan rasa tidak nyaman dan mengancam jiwa. Tujuan penelitian ini untuk melihat tingkat kecemasan yang dapat muncul atau dirasakan oleh pasien yang mendapat perawatan di IGD RS Bhayangkara. Metode penelitian ini menggunakan desain penelitian deskriptif dengan menggunakan kuisioner HARS (Hamilton Rating Scale for Anxiety) sebagai alat ukur untuk mengetahui tingkat kecemasan. Tingkat kecemasan dibagi menjadi 5 tingkatan, yaitu tidak ada kecemasan, kecemasan ringan, kecemasan sedang, kecemasan berat dan kecemasan berat sekali. Sampel yang digunakan yaitu pasien yang berkunjung di IGD RS Bhayangkara Manado yakni berjumlah 69 responden. Kesimpulan hasil penelitian didapatkan bahwa dari 69 responden yang diteliti, sebanyak 47 responden $(68,1 \%)$ mengalami kecemasan berat.
\end{abstract}

Kata kunci: Kecemasan, Instalasi Gawat Darurat 


\section{PENDAHULUAN}

Cemas merupakan suatu perasaan yang muncul ketika seseorang dihadapkan pada keadaan yang mengancam jiwa. Cemas yang berlebihan akan menimbulkan gangguan kecemasan (Dean, 2016). Kecemasan membuat individu merasa tidak nyaman dan merasa takut dengan lingkungan sekitarnya. Pada situasi tertentu kecemasan dapat diartikan sebagai sinyal yang membantu individu bersiap untuk mengambil tindakan dalam menghadapi suatu ancaman (Sutejo, 2017).

Kecemasan ditandai dengan adanya perasaan tegang, khawatir dan ketakutan. Selain itu terdapat perubahan secara fisiologis, seperti peningkatan denyut nadi, perubahan frekuensi napas, serta perubahan tekanan darah. Kecemasan dapat terjadi pada tiap individu pada sesuai dengan situasi dan kondisi di lingkungan sekitarnya (Hartono, 2012). Kecemasan terjadi karena adanya faktor-faktor yang mempengaruhi, yakni dari individu sendiri atau pun dari lingkungan sekitar (Sutejo, 2017).

Takut dan cemas merupakan emosi yang dirasakan oleh pasien saat memasuki sarana pelayanan kesehatan. Perawatan di Gawat Darurat membuat pasien takut dan cemas saat mendapatkan perawatan. (Wagley \& Newton, 2010). Pelayanan Kegawatdaruratan merupakan tindakan medis yang dibutuhkan oleh pasien gawat darurat dalam waktu segera untuk menyelamatkan nyawa dan pencegahan kecacatan. Gawat darurat merupakan keadaan klinis yang membutuhkan tindakan medis segera untuk penyelamatan nyawa dan pencegahan kecacatan (PERMENKES RI No. 47 tahun 2018).

Long (2006), intervensi keperawatan yang diberikan di Intalasi Gawat Darurat untuk menyelamatkan jiwa dilakukan ketika keadaan fisiologi pasien terancam, tindakan ini mencakup pemberian medikasi darurat, melakukan resusitasi kardiopulmonal. Kegiatan ini merupakan tindakan menyelamatkan jiwa yang dapat menyebabkan kecemasan, karena mengancam integritas tubuh. Keperawatan gawat darurat sebagai pelayanan yang melintasi semua spesifikasi tersebut, dan termasuk pelayanan perawatan yang meliputi kelahiran, kematian, pencegahan injuri, kesehatan wanita, penyakit dan penyelamatan kehidupan serta penyelamatan anggota tubuh (Kurniati dkk, 2007).

Studi menunjukkan pasien yang masuk ke instalasi gawat darurat memiliki kemungkinan untuk mengalami kecemasan yang tinggi. Umumnya pasien dengan kecemasan akan sulit unutk melakukan aktivitas. Pasien akan mengurangi aktivitas dengan alasan pasien takut akan salah bertindak atau akan merasa tidak nyaman dengan apa yang dilakukan (Wagley \& Newton, 2010).

Penelitian dengan judul Gambaran Tingkat Kecemasan Pasien di Instalasi Gawat Darurat RSUD Panembahan Senopati Bantul dilakukan pada 68 pasien. Didapatkan hasil sebanyak 28 pasien atau 41,2\% mengalami kecemasan berat (Furwanti, 2014). Penelitian lainnya dengan judul Hubungan Komunikasi Terapeutik Perawat dengan Kecemasan Pasien di Ruang Triase Instalasi Gawat Darurat Hospial Nacional Guido Valadares 53 pasien menunjukkan sebanyak 29 pasien mengalami kecemasan berat yang ditunjukkan dengan rasa tidak tenang saat berada di Instalasi Gawat Darurat (de Araujo, 2015).

Data awal diambil pada bulan Januari 2019 sampai Juni 2019 di Instalasi Gawat Darurat RS Bhayangkara. Jumlah kunjungan pasien di Instalasi Gawat Darurat berjumlah 226 pasien dengan rentang usia 5 sampai 68 tahun. 3 dari 5 pasien yang mendapat perawatan di Instalasi Gawat Darurat Rumah Sakit Bhayangkara mengalami kecemasan yang ditandai dengan wajah merah, bersikap tegang dan tidak tenang. Dengan data kunjungan tersebut penelitian ini dilakukan untuk melihat tingkat kecemasan yang muncul pada pasien di IGD Rumah Sakit Bhayangkara Manado. 


\section{METODE PENELITIAN}

Penelitian ini menggunakan metode deskriptif yang bertujuan untuk mendapatkan gambaran terkait tingkatan kecemasan pasien di Instalasi Gawat Darurat Rumah Sakit Bhayangkara Manado. Populasi merupakan keseluruhan julah pasien yang ada di Instalasi Gawat Darurat Rumah Sakit Bhayangkara.

Populasi selama 6 bulan terakhir yaitu 226 pasien. Teknik pengambilan sampel menggunakan Rumus Slovin dan didapatkan sampel berjumlah 69 responden. Sampel yang digunakan yaitu pasien yang berada di IGD RS Bhayangkara Manado. Sampel yang digunakan yaitu responden yang telah bersedia untuk menjadi sumber dalam penelitian ini.

Penelitian ini menggunakan instrument penelitian yaitu kuisioner HARS (Hamilton Rating Scale for Anxiety). Sebelum kuisioner dibagikan kepada responden, peneliti menjelaskan terlebih dahulu maksud dan tujuan dari penelitian. Selain itu peneliti juga menanyakan responden bersedia untuk mengisi kuisioner yang ada, jika responden bersedia maka diberikan surat persetujuan (Informed Consent).

Kuisioner yang digunakan menilai tingkat kecemasan pasien. Dengan menggunakan HARS (Hamilton Rating Scale for Anxiety), ditemukan ada 5 tingkatan kecemasan dengan penjumlahan skoring. Skor $\leq 14$ tidak ada kecemasan, skor 14-20 kecemasan ringan, skor 21-27 kecemasan sedang, skor 28-41 kecemasan berat dan skor 42-56 kecemasan berat sekali (Furwanti, 2014).

\section{HASIL dan PEMBAHASAN}

Karakteristik Responden

Tabel 1. Distribusi Frekuensi berdasarkan Jenis Kelamin di IGD RS Bhayangkara Manado

\begin{tabular}{lcc}
\hline Jenis kelamin & n & \% \\
\hline Laki-laki & 32 & 46,4 \\
Perempuan & 37 & 53,6 \\
\hline Total & $\mathbf{6 9}$ & $\mathbf{1 0 0}$ \\
\hline
\end{tabular}

(Sumber:Data Primer, 2019)
Berdasarkan Tabel 1, diketahui bahwa sebagian besar responden berjenis kelamin perempuan yakni 37 responden $(53,6 \%)$. Sedangkan responden laki-laki sebanyak 32 responden (46,4\%). Pengambilan sampel dilakukan dengan accidental sampling, sehingga antara perempuan dan laki-laki tidak seimbang.

Tabel 2. Distribusi Frekuensi Berdasarkan Umur di IGD RS Bhayangkara Manado.

\begin{tabular}{lcc}
\hline Umur Respon & n & \% \\
\hline $15-29$ & 41 & 59,4 \\
$30-39$ & 3 & 4,3 \\
$40-49$ & 9 & 13,0 \\
$50-59$ & 8 & 11,6 \\
$60-70$ & 8 & 11,6 \\
\hline Total & $\mathbf{6 9}$ & $\mathbf{1 0 0}$ \\
\hline
\end{tabular}

(Sumber:Data Primer, 2019)

Berdasarkan Tabel 2 diketahui bahwa responden terbanyak dengan rentang usia 15-29 tahun yaitu sebanyak 41 responden $(59,4 \%)$. Responden dengan rentang usia 30-39 tahun sebanyak 3 responden $(4,3 \%)$ dan usia 40-49 sebanyak 9 responden $(13,0 \%)$. Selain itu umur 5059 tahun dan 60-70 tahun masing-masing sebanyak 8 responden $(11,6 \%)$.

Tabel 3. Distribusi Tingkat Kecemasan Pasien IGD RS Bhayangkara Manado.

\begin{tabular}{lcc}
\hline Tingkat Kecemasan & n & \% \\
\hline Tidak ada Kecemasan & 2 & 2,9 \\
Kecemasan Ringan & 15 & 21,7 \\
Kecemasan Sedang & 4 & 7,2 \\
Kecemasan Berat & 47 & 68,1 \\
Kecemasan Berat Sekali & 0 & 0 \\
\hline Total & $\mathbf{6 9}$ & $\mathbf{1 0 0}$ \\
\hline (Sumber:Data Primer, 2019) &
\end{tabular}

Berdasarkan Tabel 3 didapatkan bahwa sebagian besar responden mengalami kecemasan berat yakni sebanyak 47 responden $(68,1 \%)$. Sebanyak 2 responden (2,9\%) mengalami kecemasan ringan, 15 responden $(21,7 \%)$ mengalami kecemasan ringan, dan 4 responden $(7,2 \%)$ mengalami kecemasan sedang. Pada 
penelitian ini tidak ditemukan responden dengan tingkat kecemasan berat sekali.

Cemas merupakan suatu perasaan yang muncul ketika seseorang dihadapkan pada keadaan yang mengancam jiwa. Cemas yang berlebihan akan menimbulkan gangguan kecemasan (Dean, 2016). Kecemasan membuat individu merasa tidak nyaman dan merasa takut dengan lingkungan sekitarnya. Pada situasi tertentu kecemasan dapat diartikan sebagai sinyal yang membantu individu bersiap untuk mengambil tindakan dalam menghadapi suatu ancaman (Sutejo, 2017). Kecemasan dapat berupa bentuk emosional yang tidak menyenangkan dan merupakan pengalaman yang samar-samar. Kecemasan dapat menimbulkan rasa tidak nyaman dan dan tidak berdaya. Seseorang yang cemas akan terlihat dari keadaan fisiknya. Keadaan fisik seseorang dapat menunjukkan tingkat kecemasan yang dirasakannya. Perubahan frekuensi pernapasan, pengingkatan denyut nadi dan perubahan tekanan darah dapat menunjukkan bahwa individu tersebut mengalami kecemasan (Sutejo, 2017). Kecemasan merupakan hal yang sering terjadi, akan tetapi sulit untuk didiagnosa terutama pada usia lanjut. Individu pada usia lanjut biasanya mengalami depresi, gangguan pola tidur, sering mengkonsumsi obat-obatan, penurunan kemampuan dan memiliki potensi yang membahayakan hidupnya. Gangguan kecemasan merupakan interaksi yang kompleks dari pengaruh biologis, pengaruh lingkungan sekitar, dan mekanisme psikologis (Hellwig \& Domschke, 2019).

Penanganan kegawatdaruratan sering kali menimbulkan rasa takut dan cemas baik kepada pasien ataupun keluarga pasien. Aspek positif dari keterlibatan keluarga dapat mengurangi kecemasan pada pasien. Selain itu keterlibatan keluarga juga berpengaruh terhadap kepuasan, penurunan kecemasan peningkatan kualitas perawatan, penurunan depresi pada pasien dan lamanya perawatan (Alizera et.al, 2019).
Karakteristik responden pada penelitian ini diantaranya nama, umur dan jenis kelamin. Nama responden yang diteliti dirahasiakan, pada lembar persetujuan dan kuisioner nama responden hanya berupa inisial. Karakteritik responden yang ditemukan pada penelitian ini berdasarkan umur dan jenis kelamin. Hasil penelitian menunjukkan responden terbanyak yaitu responden pada rentang usia 15-29 tahun. Sedangkan responden yang paling sedikit pada rentang usia 3039 tahun. Berdasarkan hasil yang didapatkan bahwa sebagian besar responden yang ditemui yakni terdapat 37 responden (54\%) yakni responden perempuan.

Hasil penelitian ini menunjukkan jumlah responden yang memiliki kecemasan terbanyak yaitu pada umur 15 sampai 29 tahun yang berjumlah 41 responden. Kecemasan dapat dipengaruhi oleh faktor umur. Long mengatakan, masalah kecemasan akan mempengaruhi konsep diri seseorang terutama pada umur yang lebih muda (Furwanti, 2014). Seseorang yang dengan umur yang lebih tua secara objektif memiliki kematangan yang terlihat dari pengalaman, pengetahuan, keterampilan, sertra kemandiriannya. Hal ini dapat membantu indvidu tersebut dalam menyelesaikan masalah kecemasan (Furwanti,2014). Faktor jenis kelamin juga mempengaruhi kecemasan seseorang. Pada penelitian ini ditemukan bahwa sebagian besar responden berjenis kelamin perempuan. Umumnya laki-laki memiliki mental atau pemikiran yang lebih kuat terhadap suatu hal yang dianggap dapat mengancam dirinya dibandingkan dengan perempuan. Laki-laki lebih memiliki banyak pengalaman dibandingkan perempuan, hal ini dibuktikan bahwa laki-laki memiliki lebih banyak interaksi dengan lingkungan luar dibandingkan dengan perempuan (Furwanti, 2014).

Hasil penelitan menunjukkan bahwa jenis penyakit yang diderita oleh responden juga menjadi faktor pendukung 
munculnya kecemasan. Faktor pendukung lainnya yakni pengalaman dari pasien, pengalaman pengobatan serta respon dari tindakan medis yang diterima. Dari penelitian ini ditemukan pasien masuk ke IGD dengan keluhan yang berbeda. Terdapat pasien yang masuk karena kecelakaan lalu lintas, dispepsia, gawat darurat obsgyn dan lain sebagainya. Sehingga penanganan yang diberikan pun akan berbeda.

Kecelakaan lalu lintas merupakan fenomena yang sering terjadi, yang disebabkan oleh kelalaian pengguna jalan. Kecelakaan lalu lintas yang menimbulkan luka yang berat akan dapat membekas pada pikiran dan perasaan korban, sehingga korban menjadi trauma. Hal ini dapat membuat korban panik dan ketakutan bahkan dapat membuat pasien menjadi stres (Putro, 2013). Stres yang berkepanjangan akan menimbulkan rasa cemas, takut, tertekan, hilangnya rasa aman, harga diri terancam dan gelisah. Kecemasan yang berlangsung lama akan menurunkan kemampuan seseorang dalam melakukan suatu aktifitas. Kecelakaan, terutama yang berat dapat menimbulkan trauma yang mengakibatkan kecemasan (Putro, 2013).

Dispepsia merupakan gejala klinis dimana pasien merasa tidak enak atau rasa sakit di perut pada saluran cerna bagian atas. Hal ini sering terjadi pada saat makan atau sesudah makan. Perasaan ini disertai dengan rasa panas di dada, kembung, perut terasa penuh, cepat kenyang, sendawa, anoreksi, mual, muntah dan keluhan lainnya (Arimbi, 2012). Dispepsia dapat disebabkan karena adanya stres psikososial. Faktor psikis dan emosi seperti kecemasan dapat mempengaruhi fungsi saluran cerna dan mengakibatkan perubahan sekresi asam lambung, mempengaruhi kerja lambung dan mengakibatkan munculnya rasa nyeri (Arimbi, 2012).

Hasil penelitian ini ditemukan pasien obsgyn yang masuk ke IGD. Kehamilan merupakan hal yang wajar yang terjadi pada wanita produktif. Selama masa kehamilan terjadi perubahan baik fisik maupun psikis. Perubahan psikis yang muncul pada ibu hamil biasanya timbul rasa kecewa, penolakan, cemas dan sedih. Kondisi psikis akan berubah seiiring bertambahnya usia kehamilan. Ibu hamil yang tidak mempunyai persiapan untuk melahirkan akan lebih cemas dn terlihat ketakutan, dalam suatu kondisi akan terdiam atau pun menangis. Walaupun merupakan hal yang wajar, akan tetapi kenyataannya proses persalinan berdampak terhadap perdarahan, kesakitan luar biasa serta dapat menimbulkan ketakutan bahkan kematian baik ibu ataupu bayinya (Zamriati, 2013).

Kecemasan terjadi pada setiap orang. Karakteristik seseorang baik umur maupun jenis kelamin dapat mempengaruhi kecemasan dari seseorang. Hal ini disebabkan adanya perbedaan dari pengalaman dan cara berinteraksi dengan lingkungan sekitar yang dapt mempengaruhi cara seseorang dalam menghadapi suatu masalah. Pengalaman hidup seseorang, pengalaman interaksi, pengalaman menghadapi masalah, bahkan pengalaman pengobatan dapat mempengaruhi kecemasan seseorang. Orang dengan pengalaman yang lebih, akan lebih mengerti cara penyelesaian masalah yang tepat (Furwanti, 2014).

\section{SIMPULAN}

Berdasarkan hasil penelitian dan pembahasan, maka dapat disimpulkan bahwa sebagian besar pasien yang mendapat perawatan di Instalasi Gawat Darurat Rumah Sakit Bhayangkara Manado mengalami kecemasan berat.

\section{DAFTAR PUSTAKA}

Alizera Z. F., Ali A. J \& Tayebeh N. B. 2019. Comparison the Effect of Trained and Untrained Family Presence on Their Anxiety During Invasive Procedures in a Emergency Department: A Randomized Controlled Trial. Turkish Journal of Emergency Medicine. 
Arimbi A. L. D. 2012. Hubungan Antara Tingkat Kecemasan Dengan Tingkat Dispepsia Menjelang Ujian Nasional Pada Siswa Kelas IX di SMP Negeri 1 Banyudono Boyolali.

de Araujo L. M., Susilo E dan Widodo G. G. 2015. Hubungan Komunikasi Terapeutik Perawat dengan Kecemasan Pasien di Ruang Triase Instalasi Gawat Darurat Hospital Nacional Guido Valadares.

Dean, E. 2016. Anxiety. Clinicalupdate.nursingstandard.com (www.ncbi.nlm.nih.gov/pubmed/2740 $\underline{6490)}$

Furwanti, 2014. Gambaran Tingkat Kecemasan Pasien di Instalasi Gawat Darurat (IGD) RSUD Panembahan Senopati Bantul.

Hartono dan Soedarmadji, B. 2012. Psikologi Konseling Edisi Revisi. Kencana Prenada Media Group. Surabaya.

Hellwig S. \& Domschke K. 2019. Anxiety in Late Life: An Update on Pathomechanisms.

Kurniati A, Trisyani Y dan Theresia S. I. M. 2018. Keperawatan Gawat Darurat dan Bencana Sheesy. Elsevier.

Peraturan Menteri Kesehatan Republik Indonesia Nomor 47 Tahun 2018 tentang Pelayanan Kegawatdaruratan.

Putro, A. T. H. 2013. Dampak Psikologis Kecelakaan Lalu Lintas.

Sutejo. 2017. Keperawatan Jiwa Konsep dan Praktik Asuhan Keperawatan Kesehatan Jiwa: Gangguan Jiwa dan Psikososial. Pustaka Baru Press.. Yogyakarta.

Wagley L. K and Newton S. E. 2010. Emergency Nurses' Use of PsychosocialNursing Interventions for Management of ED Patient Fear and Anxiety.
Zamriati W. O., Hutagaol E dan Wowiling F. 2013. Faktor-Faktor yang Berhubungan dengan Kecemasan Ibu Hamil Menjelang Persalinan Di Poli KIA PKM Tuminting. 